\title{
Derecho a recurso, destitución y delegación de funcionarios públicos. Consideraciones en torno a un dictamen de la Contraloría General de la República
}

Patricio Ponce Correa*

\begin{abstract}
El presente trabajo comenta el Dictamen NE30045-2020, emitido por la Contraloría General de la República en agosto de 2020, y aborda sus alcances en relación al derecho a recurso como mecanismo de impugnación administrativa frente a la aplicación específica de una medida disciplinaria expulsiva, así como también, en sus efectos generales respecto a la revisión jerárquica de un acto administrativo dictado en ejercicio de potestades delegadas.
\end{abstract}

Palabras clave: Derecho a recurso, delegación, destitución, Contraloría General de la República.
This paper comments on opinion $N^{\circ}$ E30045-2020, issued by the Office of the Comptroller General of the Republic in August 2020. It addresses its scope in relation to the right to appeal as a challenge mechanism against an expulsion disciplinary measure, as well as its effects regarding the hierarchical review of an administrative act issued in the exercise of delegated powers.

Keywords: Right to appeal, delegation, removal of public officials, Comptroller General of the Republic.

\section{Introducción}

La destitución, medida disciplinaria de mayor gravedad contemplada en el EA, envuelve una afectación intensa y prolongada de derechos fundamentales tales como la libertad de acceso a cargos públicos y libertad de trabajo. Ello exige sujetar su aplicación a estándares más exi-

\footnotetext{
* Profesor de Derecho Administrativo y Derecho Constitucional, Escuela de Derecho, Universidad de Tarapacá, Arica, Chile. Doctorando en Derecho, Universidad de los Andes, Chile. Abogado, Licenciado en Ciencias Jurídicas de la Universidad de Tarapacá. Magíster en Ciencias Jurídicas, Universidad de Tarapacá. Dirección postal: Cardenal Caro Nº 348, Arica, Chile. Correo electrónico pponce@academicos.uta.cl.
}

Recibido el 6 de noviembre de 2020 y aceptado el 10 de diciembre de 2020. 
gentes, tanto en el ámbito procedimental como orgánico, que los dispuestos respecto de otras sanciones.

Dentro de tales garantías, podemos advertir que la medida expulsiva debe ser adoptada por la máxima jefatura del servicio y que su aplicación queda sujeta, por regla general, a un procedimiento sancionatorio más desarrollado. Este último contempla un régimen de impugnación administrativa ordinaria, a partir del cual podemos identificar un derecho a recurso en favor del afectado, que integra los recursos de reposición y apelación.

Pero el texto de la regla recursiva prevista en el EA respecto del acto administrativo sancionatorio adoptado en virtud de un sumario administrativo, no descarta la apelación para el caso en que la decisión es adoptada por la máxima superioridad del servicio respectivo. Dicha limitación sí aparece en la disposición que regula la investigación sumaria y, por cierto, en el artículo 59 de la LBPA, que restringen la vía recursiva en estos casos a la sola reposición.

El dictamen en comento aborda el derecho a recurso en estos casos. Frente a la eventual aplicación supletoria de la LPBA, así como también, ante una alteración de la garantía orgánica antes referida, cuando la medida expulsiva es adoptada por una jefatura inferior en virtud de delegación.

\section{El Dictamen NE30045-2020 de la Contraloría General de la Repú- blica}

Este dictamen fue emitido por la Contraloría General de la República el 25 de agosto de 2020 en respuesta a un requerimiento interno, formulado por su Departamento de Previsión Social y Personal. Su objeto fue interpretar si resulta o no admisible que, frente a una medida de destitución aplicada por el ministro, o subsecretario por delegación, a funcionarios de su dependencia, estos últimos apelen de ella para ante el presidente de la República.

La consulta surge a partir del texto del artículo 141 del EA ${ }^{1}$, el cual sostiene que en contra de la resolución sancionatoria disciplinaria proceden los recursos de reposición y apelación subsidiaria, sin distinguir los casos en que dicho acto fuere dictado por la máxima jefatura del servicio. En tanto que, por su parte, el artículo 59 de la LBPA prescribe que en contra de las resoluciones del jefe superior solo procede reposición.

Luego de advertir la existencia de dos precedentes que abogaban por la procedencia del recurso de apelación en tales términos (dictámenes

\footnotetext{
1 “En contra de la resolución que ordene la aplicación de una medida disciplinaria, procederán los siguientes recursos:

“a) De reposición, ante la misma autoridad que la hubiere dictado, y

“b) De apelación ante el superior jerárquico de quien impuso la medida disciplinaria.

“El recurso de apelación solo podrá interponerse con el carácter de subsidiario de la solicitud de reposición y para el caso que esta no sea acogida.

"Los recursos deberán ser fundados e interponerse en el plazo de cinco días, contado desde la notificación, y deberán ser fallados dentro de los cinco días siguientes".
} 
$N^{\circ}$ 46001-2005 y N53520-2011), el órgano contralor se inclina esta vez por una reinterpretación y concluye que no resulta admisible tal mecanismo de impugnación respecto de la destitución aplicada por un ministro.

Pero, de paso con lo anterior, el dictamen en comento cierra también la vía recursiva jerárquica respecto de las destituciones que fueren aplicadas por un delegado del ministro; cuestión que, en el escenario planteado por la consulta, recaería en el subsecretario. Así, ya sea que la medida expulsiva fuere aplicada por el ministro o su delegado, la vía recursiva administrativa interna se agota con la sola reposición.

\section{Razonamiento explícitos e implícitos tras el Dictamen № E30045- 2020}

La especial relevancia de este dictamen radica en que aborda por vía interpretativa dos materias que han resultado tradicionalmente de difícil solución, debido a una aparente imperfección en la redacción normativa. Lo que ha motivado vaivenes jurisprudenciales al interior del propio ente contralor.

La primera de ellas, referente a la improcedencia del recurso de apelación respecto de la resolución destitutoria dictada por un ministro contra el personal de su dependencia, constituye, sin lugar a dudas, la línea interpretativa medular del dictamen, lo cual aborda directa y explícitamente. Siguiendo a Phillips², diremos que a partir de ella se colige la ratio decidendi.

La segunda, más bien indirecta, versa sobre la inadmisibilidad de reconocer un régimen recursivo jerárquico respecto de los actos ejecutados en ejercicio de potestades delegadas, lo que el pronunciamiento aborda entre líneas al plantearse como hipótesis que la destitución fuere decretada por un subsecretario como delegatario del ministro. Su carácter implícito justificaría preguntarse si encierra una segunda ratio o cabe ser considerado obiter dictum.

\section{Apelación respecto de la resolución expulsiva}

Conforme al artículo 140 del $\mathrm{EA}^{3}$, el sumario administrativo debe ser resuelto por la autoridad que dispuso su instrucción, salvo que corresponda aplicar una medida de destitución, caso en el cual la resolución será dictada por la autoridad naturalmente facultada para efectuar el nombramiento. Ello recaerá en el jefe superior del respectivo órgano administrativo, excepto en cargos de exclusiva confianza del presidente de la República ${ }^{4}$.

\footnotetext{
2 PhILLIPS 2020, 149-176.

3 "Emitido el dictamen, el fiscal elevará los antecedentes del sumario al jefe superior de la institución, el Secretario Regional Ministerial o el Director Regional de servicios nacionales desconcentrados, según el caso, quien resolverá en el plazo de cinco días, dictando al efecto una resolución en la cual absolverá al inculpado o aplicará la medida disciplinaria, en su caso. Tratándose de la medida de destitución, los antecedentes se elevarán a la autoridad facultada para hacer el nombramiento".

4 "Conforme Ley N¹8834 art. 119 la destitución es la decisión de la autoridad facultada para hacer el nombramiento, de poner término a los servicios de un funcionario, y art. 13 de la misma
} 
La Contraloría ha precisado que, en el caso de los ministerios, tal atribución recae en el ministro5; en servicios nacionales, su director nacionalb; y en órganos descentralizados territorialmente, como los servicios de salud, sus directores regionales ${ }^{7}$. En todo caso, se tratará de la autoridad facultada por ley para efectuar el nombramiento y no de aquella que ejerza esta atribución por delegación; delegar la facultad de nombrar no lleva ínsita la de destituir ${ }^{8}$.

Acontece que el texto del artículo 141 del referido estatuto, en el caso del sumario administrativo, confiere al afectado derecho a recurrir de reposición y apelación subsidiaria respecto del acto administrativo sancionatorio, sin contemplar una regla especial para el caso en que este hubiere sido dictado por el jefe superior del servicio, prevención que sí formula el artículo 126 a propósito de la investigación sumaria.

Surge así el problema de determinar si procede o no la revisión jerárquica en el caso de llegar a aplicarse una medida disciplinaria por el jefe superior de servicio, en virtud de un sumario administrativo $y$, frente a una respuesta afirmativa, ante quien. Dicha incerteza resulta especialmente atingente a la destitución pues, según señalamos antes, la facultad de aplicar esta última recae precisamente en el jefe superior en virtud de la ley.

Y es que la apelación corresponde en este caso a un recurso administrativo interno de carácter jerárquico, destinado a que el acto administrativo sancionatorio sea revisado por el superior inmediato de quien lo dictó. Al tratarse de un control interno, la revisión referida corresponde ser efectuada por órganos administrativos "de la de misma rama de donde proviene el acto examinado"9.

Así, Aldunate ha sostenido que en este caso simplemente no resulta procedente la apelación ${ }^{10}$, Celis estima improcedente dicho recurso cuando se trata del jefe superior de un órgano descentralizado, pero lo estima admisible cuando el órgano pertenece a la administración centralizada ${ }^{11}$. Caso

\footnotetext{
ley señala que el nombramiento se resolverá por los jefes superiores en los servicios públicos regidos por el estatuto administrativo, con excepción del nombramiento de los cargos de exclusiva confianza del presidente de la república". Dictamen N²3520 (1991).

5 Dictamen $N^{\circ}$ E21316 (2020).

6 Dictamen No35363 (2017).

7 Dictamen $N^{\circ} 27652$ (2016).

8 "[...] no puede inferirse que esas autoridades sean las competentes para aplicar una medida expulsiva, toda vez que dicha potestad, propia del Ministro respecto del personal de su dependencia, no les fue delegada expresamente, sin que la circunstancia de haberse delegado la facultad de designar al personal que en ella se indica, lleve implícita la facultad de destituirlo [...]". Dictamen NE21316 (2020).

9 Cordero 2015, 542. En este sentido, se ha precisado que el recurso jerárquico se formula respecto de actos administrativos dictados por un funcionario de "cualquiera de las oficinas, dependencias o empleos que forman parte del órgano público". Astorga 2016, 654.

10 Vid. Aldunate 2011, 150.

11 Vid. Celis 2015, 234.
} 
conflictual el de los ministros, pues su superior jerárquico es un órgano externo al ministerio, máxima jefatura estatal y de gobierno ${ }^{12}$.

Astorga identifica expresamente este recurso con el jerárquico previsto en el artículo 59 de la $\operatorname{LBPA}^{13}$ y, por esta vía, tocaría reconocer límites similares a los que establece dicha norma, esto es, su improcedencia respecto de actos que emanen del presidente de la República, ministros de estado y los jefes superiores de los servicios públicos descentralizados.

No obstante, razones de texto podrían conducir a la interpretación contraria, en orden a que la limitación prevista en el artículo 126 del EA para la investigación sumaria aparece claramente omitida en el texto del 141 respecto del sumario administrativo, procedimiento especialmente destinado a la aplicación de medidas disciplinarias más graves. Ello permitiría sostener que se trata de una regla recursiva legal especialmente distinta.

En el caso específico de los ministerios, la Contraloría acogió esta última interpretación en los dictámenes $N^{\circ} 46001-2005^{14}$ y $N^{\circ} 53520-2011^{15}$, tras concluir que procede apelación para ante el presidente de la República respecto de las destituciones aplicadas por los ministros de estado. El razonamiento seguido por el órgano contralor se fundó en reconocer un derecho a recurso jerárquico a partir del artículo 141 del EA y concluir que los ministros son dependientes del jefe de Estado.

Ambos pronunciamientos fueron reconsiderados por el nuevo Dictamen Nº30045-2020. En este último, el ente contralor cambia de criterio interpretativo y se inclina por concluir que el artículo 141 del EA omite precisar el régimen recursivo jerárquico aplicable al caso en que el acto administrativo sancionatorio emane del jefe superior del respectivo órgano, en este caso, un ministerio.

Así, al identificar esta apelación con el recurso jerárquico previsto en la LBPA, lleva a sostener que el artículo 59 de dicha norma contendría una disposición que, ante el silencio del EA, cobra aplicación especial y permite

\footnotetext{
12 A propósito del recurso jerárquico, precisa Bermúdez que los ministros de estado tienen un superior jerárquico, cual es el presidente de la República. Vid. Bermúdez 2014, 225.

13 Vid. Astorga 2016, 638.

14 "Consecuente con lo anterior, la medida disciplinaria de destitución aplicada a la peticionaria por el Subsecretario de Educación en virtud de las facultades delegadas por el titular de la cartera, debe entenderse impuesta por el Ministro de Educación, procediendo entonces que sea el Presidente de la República -y no el Ministro- en su carácter de superior jerárquico de este último, quien conozca y resuelva el recurso de alzada, como efectivamente ha acontecido en la especie, todo lo cual autoriza para concluir que no se ha configurado en este aspecto el vicio de ilegalidad que reclama". Dictamen No 46001 (2005).

15 "[...] en lo que atañe a la otra inquietud manifestada por la recurrente en relación con dicho proceso, es pertinente indicar que de acuerdo al artículo 141 de la citada Ley $N^{\circ} 18.834$, la resolución que aplica una medida disciplinaria, podrá apelarse ante el superior jerárquico de quien la impuso, recurso que, en el caso de medidas impuestas por un Ministro de Estado, debe ser conocido por el Presidente de la República [...]". Dictamen Nº 53520 (2011).
} 
concluir que la vía administrativa interna se agota en esos casos con la reposición ${ }^{16}$.

\section{Régimen recursivo jerárquico respecto de potestades delegadas}

Otro tema que aborda indirectamente el Dictamen $N^{\circ}$ E30045-2020 radica en determinar si procede o no el recurso jerárquico respecto de actos ejecutados en virtud de potestades delegadas. Se trata aquí de un tema que acusa una difícil solución, pues la norma legal no ofrece suficiente claridad a este respecto.

Conviene precisar que la delegación administrativa es una transferencia temporal, específica y revocable del ejercicio de determinadas potestades, o de la sola facultad de firmar, que realiza una autoridad o jefatura administrativa a un órgano o funcionario de su dependencia. Su propósito es descongestionar y hacer más eficaz la resolución de los asuntos al interior del órgano respectivo ${ }^{17}$, alterando la distribución natural de sus competencias ${ }^{18}$.

Si bien la delegación administrativa constituye una medida de cotidiana ocurrencia, su regulación general se restringe a la regla prevista en el artículo 41 de la LOCBGAE ${ }^{19}$, la cual parece albergar dos principios contradictorios. El inciso $2^{\circ}$ plantea que el delegante queda impedido de ejercer la facultad delegada sin revocar previamente la delegación (inavocabilidad particular); pero, según el literal d), este conserva el control jerárquico respecto de su delegado.

Soto Kloss sostiene, en principio, que el recurso jerárquico sería procedente respecto de los actos del delegado, dado que existe responsabilidad de

\footnotetext{
16 "[...] no procede el recurso de apelación respecto de las medidas de destitución aplicadas por un Ministro de Estado -o por el Subsecretario por delegación- a los funcionarios de su dependencia y nombrados por aquella autoridad, atendido que esta instancia recursiva se encuentra limitada por el inciso cuarto del artículo 59 de la Ley $N^{\circ} 19.880$, precepto que, a falta de regla especial en el Estatuto Administrativo, y por ser compatible con la regulación contenida en este, resulta aplicable en la especie". Dictamen Nº E30045 (2020).

17 Tal como anota Valdivia, la delegación administrativa se trata de un instituto que opera siempre "al interior de un único organismo". VALDIVIA 2018, 83.

18 Vid. CORDERO 2015, 200.

19 "El ejercicio de las atribuciones y facultades propias podrá ser delegado, sobre las bases siguientes:

“a) La delegación deberá ser parcial y recaer en materias específicas;

“b) Los delegados deberán ser funcionarios de la dependencia de los delegantes;

“c) El acto de delegación deberá ser publicado o notificado según corresponda;

“d) La responsabilidad por las decisiones administrativas que se adopten o por las actuaciones que se ejecuten recaerá en el delegado, sin perjuicio de la responsabilidad del delegante por negligencia en el cumplimiento de sus obligaciones de dirección o fiscalización; y

"e) La delegación será esencialmente revocable.

"El delegante no podrá ejercer la competencia delegada sin que previamente revoque la delegación.

"Podrá igualmente, delegarse la facultad de firmar, por orden de la autoridad delegante, en determinados actos sobre materias específicas. Esta delegación no modifica la responsabilidad de la autoridad correspondiente, sin perjuicio de la que pudiera afectar al delegado por negligencia en el ejercicio de la facultad delegada".
} 
control, pero advierte que este ejercicio posibilitaría la avocación sin necesidad de revocar y, con ello, eludir una proscripción expresa en la norma ${ }^{20}$. Quezada se inclina abiertamente por su procedencia ${ }^{21}$, en tanto Astorga lo considera así solo cuando se trata de una delegación de potestades y no de firma ${ }^{22}$.

La jurisprudencia de la Contraloría se inclinó por estimar improcedente el recurso jerárquico en un principio. Así puede verse en el Dictamen $N^{\circ} 41385-1994^{23}$, cuyo criterio va a ser reiterado, entre otros, por los dictámenes $N^{\circ} 38215-2001$, No 40436-2001, N 7704-2005 y Nº 60754-2005.

Tales pronunciamientos aluden al artículo 41 de la LOCBGAE y coligen una suerte de representación del delegante, ejercida por el delegado, de modo que, al no existir recurso respecto de lo actuado por el primero, tampoco lo habrá contra aquellas actuaciones ejecutadas por otro en su reemplazo. No obstante, nos parece con la mención de dicho artículo, el órgano de control ha debido tener en consideración la prohibición de avocación particular.

Dicha jurisprudencia va a evidenciar un cambio a partir del Dictamen No 9306-201124, que será reiterado en iguales términos por el Dictamen $N^{\circ} 19708-2011$ y luego por los dictámenes $N^{\circ} 31774-2011, N^{\circ} 49560-2011$.

Podemos identificar que este cambio interpretativo se sustenta en tres fundamentos: 1. la facultad de conocer el recurso jerárquico es distinta de la facultad cuyo ejercicio fue delegado; 2 . la autoridad delegante conserva responsabilidad por el control jerárquico, lo que justifica el conocimiento de dicho recurso; y 3. el artículo 141 del EA otorga un derecho a la doble instancia en los procedimientos disciplinarios.

\footnotetext{
20 SOTO 1989, 142.

21 Quezada 2017, 103.

22 Astorga 2016, 661.

23 "[...] cuando autoridades administrativas imponen medidas disciplinarias por delegación de funciones del jefe superior del servicio, los afectados no pueden interponer el eventual recurso de apelación que ante esta última autoridad pueda existir, porque aquellas jefaturas, al suscribir los documentos que aplican las sanciones, están representando a la superioridad máxima de la institución, por lo que debe entenderse que quien las impone es esta última a través de un delegado". Dictamen N41385 (1994).

24 "[...] el conocimiento y resolución de los recursos administrativos por parte de la superioridad respectiva, al corresponder a una potestad distinta de aquella que ha sido delegada, no importa vulnerar la regla que exige la previa revocación de la delegación, prevista en el inciso segundo del artículo 41 del texto orgánico constitucional antes referido".

"[...] procede afirmar que la delegación de facultades en las Directoras Regionales, reducida actualmente, en lo que atañe al acto examinado, a la aplicación de las medidas disciplinarias de censura y multa, no importa que la Vicepresidenta Ejecutiva haya transferido la potestad revisora de la que es titular, motivo por el cual la decisión de la autoridad regional de que se trata, en orden a declarar improcedente el recurso de apelación contemplado en el artículo141 del Estatuto Administrativo, deducido por la afectada en contra de la multa aplicada a su respecto, aduciendo que actúa con atribuciones delegadas, no se ajustó a la jurisprudencia vigente sobre la materia". Dictamen No 9306 (2011).
} 
Ahora, si bien estos últimos pronunciamientos no aparecen expresamente reconsiderados por el Dictamen NE30045-2020, lo cierto es que la hipótesis que este último manifiesta, en orden a considerar que la destitución pueda ser aplicada por un delegatario del ministro y negar también en este caso la procedencia del recurso jerárquico, implícitamente, importa desestimar que tal actuación pueda ser revisada por el delegante.

Si bien nos parece que el criterio jurisprudencial en esta materia es evidente, cierto resulta que la hipótesis de delegación fluye del requerimiento y no recibe una consideración particular en la fundamentación del dictamen, de modo que existirían argumentos para considerarla una declaración tangencial. Frente a ello tocará analizar la jurisprudencia posterior que el órgano pueda emitir en esta materia para reafirmar o desestimar este punto.

\section{III. ¿El dictamen en comento infringe el derecho a recurso administrativo?}

A partir de la doctrina procesal se ha llegado a identificar principios indispensables para el desarrollo de un proceso como mecanismo legítimo de defensa de los derechos de las personas. Las nociones de debido proceso y tutela judicial efectiva resultan hoy consagrados a nivel constitucional y tratados internacionales como una garantía esencial para la protección de los derechos humanos.

Tales principios, surgidos en el contexto de la actividad jurisdiccional, han expandido su campo de aplicación a los procedimientos administrati$\operatorname{vos}^{25}$, ejercicio este último no exento de complejidades y forzosas distinciones, ante las sustanciales diferencias que asoman entre la actividad jurisdiccional y administrativa. Así, tal como el ámbito administrativo sancionatorio ha recibido influjos de la dogmática penal, el procedimental lo ha recogido del orden procesal.

De esta forma, a partir de su consagración constitucional, la noción de debido proceso ha recibido permanente alusión por la jurisprudencia de la Contraloría, especialmente en el ámbito disciplinario. Por ejemplo, puede verse el reconocimiento del debido proceso en materia administrativa ya en un dictamen de $1983^{26}$.

\footnotetext{
25 "Es un derecho humano el obtener todas las garantías que permitan alcanzar decisiones justas, no estando la administración excluida de cumplir con este deber. Las garantías mínimas deben respetarse en el procedimiento administrativo y en cualquier otro procedimiento cuya decisión pueda afectar los derechos de las personas". Caso Baena Ricardo y otros Vs. Panamá (2001), párr. 127.

26 "[...] devuelve resolución de academia superior de ciencias pedagógicas de Santiago por la cual se establecen sanciones para las personas que atenten en contra de académicos, funcionarios o alumnos, o contra los recintos de esa academia, por cuanto ella se limita a disponer al respecto una investigación sumaria que no podrá exceder de 48 horas, omitiendo establecer los preceptos mínimos relativos al debido proceso que son exigibles en una normativa de esta naturaleza, acorde constitución pol art/19 num/3". Dictamen N 435 (1983).
} 
No obstante, somos de la idea que la asimilación de nociones surgidas al alero de otras disciplinas jurídicas no pasa por un acto de simple extrapolación, sino que requieren ser construidas a partir de la propia dogmática administrativa, pues solo así pueden resultar conciliables con los rasgos propios de esta rama jurídica.

Dentro de las garantías del debido proceso, el derecho a defensa y, en especial, el derecho a recurso como un elemento de este último ${ }^{27}$, requieren ser analizados a la luz de las normas y principios propios del ámbito administrativo. A este respecto, a partir del principio de impugnabilidad previsto en los artículos 15 y 59 de la LBPA, así como el 10 de la LOCBGAE, cabe identificar un régimen recursivo general ${ }^{28}$.

Tal régimen permite efectivamente reconocer al afectado por un acto administrativo un derecho a recurso en este ámbito, cuestión esta última que, en el caso de la aplicación de una medida disciplinaria, recaerá en el sancionado. Pero el ejercicio de tal derecho requiere ser construido sin desconocer la orgánica administrativa, lo que en este caso obliga a entenderlo como un control interno y, en el caso de la apelación, jerárquico.

Una cuestión fundamental -entre varias ${ }^{29}$ - que separa la generalidad de la actividad procesal de carácter jurisdiccional de la administrativa, radica precisamente en el carácter indiscutible que adquiere, bajo ciertas condiciones, la decisión adoptada en virtud la primera. Dicha cuestión escapa al ámbito administrativo cuyas decisiones, aun cuando queden a firme, no gozan de cosa juzgada y pueden ser revisadas.

Esto permite que la revisión de la decisión administrativa admita diversas fórmulas de producción, como recursos administrativos, revisión de oficio,

\footnotetext{
27 El Tribunal Constitucional ha señalado que las garantías del debido proceso en el ámbito administrativo exigen consagrar un derecho a recurso: "Que un segundo requisito exigido a todo procedimiento administrativo, para ser estimado justo y racional en lo que a este caso importa, radica en la posibilidad de impugnar la decisión que concluye su tramitación. Especialmente cuando esa resolución pueda favorecer a uno y perjudicar a otros, con falta de fundamento o de justificación [...]". Sentencia TC Rol Nº613 (2019), c. 6%).

28 Así, por ejemplo, la Contraloría ha señalado: "[...] el artículo 15 de la citada Ley N 19.880 en concordancia con los artículos $3^{\circ}$ y 10 de la Ley No 18.575, Orgánica Constitucional de Bases Generales de la Administración del Estado-, desarrolla el principio de impugnabilidad al precisar que 'Todo acto administrativo es impugnable por el interesado mediante los recursos administrativos de reposición y jerárquico, regulados en esta ley, sin perjuicio del recurso extraordinario de revisión y de los demás recursos que establezcan las leyes especiales'".

"En concordancia con lo expuesto y en armonía con lo indicado, entre otros, en los dictámenes $N^{\circ}$ 62.496, de 2008, $N^{\circ}$ 54.097, de 2009 y $N^{\circ} 34.217$, de 2013, todos de este origen, y al contemplar el referido artículo $5^{\circ}$ del antedicho reglamento la figura de la 'evaluación docente objetada', sin prever una instancia administrativa de reclamación, se aplican supletoriamente los preceptos de la citada Ley $N^{\circ} 19.880$, en particular su artículo 59, por lo que procede el recurso de reposición ante el funcionario o autoridad que resolvió tal objeción y, en subsidio, el jerárquico, ante su superior". Dictamen Nº4239 (2014).

29 "La imparcialidad del juzgador, la invariabilidad de la decisión firme, la facultad de ejecutar la resolución coactivamente y la posibilidad de requerir la inaplicabilidad de un precepto legal decisorio, parecen ser algunos de los elementos distintivos". PONCE 2020, 189.
} 
controles administrativos externos, sin perjuicio del contencioso administrativo. De modo que las limitaciones propias de la estructura administrativa, en tanto concibe jefaturas superiores cuyas decisiones agotan la vía interna, no excluye otros mecanismos de impugnación y, menos aún, causa indefensión.

En otras palabras, dicha orgánica no permitiría, sin desnaturalizar el recurso jerárquico, concebir una doble instancia. ¿De qué forma se logra identificar una jefatura superior llamada a conocer de una apelación al interior de un servicio, si el acto objeto de revisión emana precisamente de su máxima autoridad? La respuesta parece ser una: fuera de ese servicio, transformando así un recurso interno en externo.

Advertir en el artículo 141 del EA una imperfecta redacción que omite el supuesto en que el acto sancionatorio es dictado por la máxima autoridad de un ministerio o un servicio descentralizado, y suplir su silencio con la excepción prevista en el artículo 59 de la LBPA no nos parece, en ese entendido, una afectación del derecho recursivo.

Por el contrario, ofrece una vía interpretativa importante para llegar a integrar otros vacíos normativos presentes en el régimen procedimental disciplinario previsto en el EA, que constituyen afectaciones intensas del derecho a recurso y cuya aplicación no ha recibido, hasta ahora, acogida en la jurisprudencia de la entidad contralora, como podría ser, por ejemplo, la proscripción de la reformatio in peius prevista expresamente en el artículo 41 de la LBPA.

\section{Conclusión}

El Dictamen N E30045-2020 de la Contraloría General de la República modifica dos líneas jurisprudenciales que refieren, la primera, al régimen recursivo jerárquico frente al ejercicio de la potestad de destitución y, la segunda, más bien implícita en el pronunciamiento, a la procedencia de dicho recurso respecto de actuaciones emitidas en ejercicio de atribuciones delegadas.

El criterio reseñado concluye la improcedencia del recurso jerárquico frente a la aplicación de medidas disciplinarias por parte del ministro, o su delegatario, al personal de su dependencia, por aplicación de lo previsto en el artículo 59 de la LBPA, interpretado como complementario del artículo 141 del EA.

Dicha interpretación, en nuestra opinión, más que afectar el derecho a recurso administrativo, ofrece una vía de impugnación armónica con la orgánica administrativa y los principios generales del régimen recursivo jerárquico. Ello, a su vez, podría abrir la puerta a integrar otros principios previstos en dicha norma y omitidos en el EA, e incluso llegar a fortalecer el derecho a defensa en el ámbito disciplinario. 


\section{Bibliografía citada}

Aldunate Ramos, F. (2011). La responsabilidad administrativa y procedimientos disciplinarios. Thomson Reuters.

Astorga Valenzuela, C. (2016). Los recursos administrativos (T II). Círculo Legal Editores.

Bermúdez Soto, J. (2014). Derecho administrativo general. Thomson Reuters.

Celis Danzinger, G. (2015). Derecho administrativo disciplinario. El Jurista.

Cordero Vega, L. (2015). Lecciones de derecho administrativo. Thomson Reuters.

Phillips Letelier, J. (23 de junio de 2020). La fuerza obligatoria del precedente de la Contraloría General de la República. Una regla chilena de stare decisis. Revista de Derecho Administrativo Económico. http://redae.uc.cl/index.php/REDAE/article/view/16203

Ponce Correa, P. (25 de mayo de 2020). La consignación y toma de posesión material por expropiación como gestión de jurisdicción voluntaria: ¿una garantía adecuada de defensa de los derechos e intereses del expropiado? Revista de Derecho Administrativo Económico. http://redae.uc.cl/index.php/REDAE/article/view/16209/13261

Quezada Rodríguez, F. (2017). La delegación en el derecho administrativo chileno. En J. I. Nuñez (Dir.) y R. Urzúa Arce (Coord.), Temas misceláneos y actas del Primer Encuentro de Investigadores Jóvenes en Derecho Público y Teoría del Derecho (pp. 81-110). Ediciones Universidad Finis Terrae.

Soto Kloss, E. (1989). La delegación en el derecho administrativo chileno. Revista de Derecho Público (45-46), 115-147.

Valdivia, J. M. (2018). Manual de derecho administrativo. Tirant lo Blanch.

\section{Normativa citada}

Constitución Política de la República de Chile. Decreto N 100. 15 de septiembre de 2005. D.O. N $\mathrm{N}^{\circ} 38.268$.

Ley N 18.575 de 1986. Orgánica Constitucional sobre Bases Generales de la Administración del Estado. 12 de noviembre de 1986. D.O. № 32.640.

Ley N 18.834 de 1989. Aprueba Estatuto Administrativo. 15 de septiembre de 1989. D.O. $N^{\circ} 33.479$.

Ley N 19.880 de 2003. Establece bases de los procedimientos administrativos que rigen los actos de los órganos de la Administración del Estado. 22 de mayo de 2003. D.O. $N^{\circ} 37.570$.

\section{Jurisprudencia}

Jurisprudencia Judicial

Caso Baena Ricardo y otros vs. Panamá. Caso 11.325. Juicio. Parágrafo 127 (2 de febrero de 2001).

Sentencia TC Rol No 6613 (2019): Tribunal Constitucional, 21 de noviembre de 2019.

\section{Jurisprudencia administrativa}

Contraloría General de la República. Dictamen N 435, 7 de enero de 1983.

Contraloría General de la República. Dictamen N²3520, 1 de octubre de 1991.

Contraloría General de la República. Dictamen N 41385, 2 de diciembre de 1994.

Contraloría General de la República. Dictamen N³8215, 17 de octubre de 2001.

Contraloría General de la República. Dictamen N 40436, 31 de octubre de 2001.

Contraloría General de la República. Dictamen N 7704, 4 de febrero de 2005.

Contraloría General de la República. Dictamen No 46001, 30 de septiembre de 2005.

Contraloría General de la República. Dictamen Nº 60754, 29 de diciembre de 2005.

Contraloría General de la República. Dictamen N 9306, 14 de febrero de 2011.

Contraloría General de la República. Dictamen N 19708, 31 de marzo de 2011.

Contraloría General de la República. Dictamen N³1774, 18 de mayo de 2011.

Contraloría General de la República. Dictamen N 49560, 8 de agosto de 2011. 
Contraloría General de la República. Dictamen N 53520, 24 de agosto de 2011. Contraloría General de la República. Dictamen № 27652, 14 de abril de 2016.

Contraloría General de la República. Dictamen N³5363, 2 de octubre de 2017.

Contraloría General de la República. Dictamen NE21316, 23 de julio de 2020.

Contraloría General de la República. Dictamen Nº E30045, 25 de agosto de 2020.

\section{Siglas y abreviaturas}

CGR Contraloría General de la República.

EA Estatuto Administrativo.

LBPA Ley que establece Bases de los Procedimientos Administrativos que rigen los Actos de los Organos de la Administración del Estado.

LOCBGAE Ley Orgánica Constitucional de Bases Generales de la Administración del Estado. párr. párrafo. 